\title{
VENOUS ADMIXTURE TO THE PULMONARY CIRCULATION IN HUMAN SUBJECTS BREATHING 100 PER CENT OXYGEN *
}

\author{
By SAMI I. SAID ANd CHANDRA M. BANERJEE
}

(From the Department of Medicine and the Pulmonary Laboratory, Medical College of Virginia, Richmond, Va.)

(Submitted for publication August 20, 1962; accepted December 12, 1962)

At any given time, the alveolar-arterial oxygen partial pressure difference $(\mathrm{AaD})$ may be due to one or more of the three following mechanisms $(1-5): 1)$ failure of pulmonary capillary blood to come to complete equilibrium with alveolar gas ; 2) uneven ventilation perfusion ratios; and 3) admixture of venous blood by direct shunting.

The first mechanism causes the diffusion component of the $\mathrm{AaD}$, relating to diffusion across the alveolar-capillary membrane as well as chemical reaction rates of oxygen with hemoglobin $(6,7)$. The second mechanism accounts for the "distribution" component, and the third is spoken of as the "true," "pure," or "anatomical" shunt, or the "direct" venous admixture component.

When the inspired oxygen tension is low, as at high altitude or during breathing of hypoxic mixtures, particularly if either condition is combined with exercise, the diffusion component increases, whereas those due to direct venous admixture and to uneven ventilation-perfusion ratios diminish. These changes are used to determine the pulmonary diffusing capacity for oxygen $(1-3,8)$. On the other hand, breathing $100 \%$ oxygen increases the $\mathrm{AaD}$ due to direct venous-arterial shunting, and virtually eliminates all other components (9).

The role of diffusion impairment in the causation of arterial hypoxemia has been recently reevaluated (10), and a number of newer approaches have permitted a more precise definition of the distribution of ventilation-perfusion ratios and of its importance in gas exchange (11-15). There have been relatively few reports, however, on the

* Presented in part at the joint meeting of the American Federation for Clinical Research and the American Society for Clinical Investigation, April 30, 1961, Atlantic City, N. J. This study was supported by U. S. Public Hearth Service research career program award HE-K3-18,432 and grant H-4226 (C3) from the National Heart Institute, and by a research grant from the American Heart Association. incidence and magnitude of increased "direct" venous admixture in pulmonary disease $(10,16-19)$. The paucity of such reports has probably been due to the lack of practical techniques for the accurate measurement of blood oxygen tension at high levels.

This paper has two purposes. The first is to report on the size and composition of the AaD, measured during air and during oxygen breathing in 6 normal subjects, 15 patients with pulmonary emphysema, 14 with diffuse alveolar-capillary disease, and 12 markedly obese patients. The second is to present conclusions, derived from these results, on the role of "true" shunt in the pathogenesis of arterial hypoxemia in these patients.

\section{METHODS}

Patients. Three groups of patients and one of normal controls were examined. Group I consisted of 15 patients with clinical, X-ray, and laboratory findings of obstructive pulmonary emphysema. Group II comprised 14 patients with pulmonary diseases that appeared to involve primarily the alveolar-capillary area. All showed X-ray evidence of diffuse pulmonary infiltration or fibrosis and mild to severe impairment of lung function, including restriction of the vital capacity without spirographic evidence of airway obstructive disease, and lowering of resting arterial blood $\mathrm{PO}_{2}$ with a normal or low $\mathrm{PCO}_{2}$. The etiologic diagnoses, confirmed by lung or lymph node biopsy in four patients and by bacteriologic examination in two were: sarcoidosis (seven patients), tuberculosis (two), disseminated lupus erythematosus (one), pulmonary alveolar proteinosis (one), Hand-Schuller-Christian disease (one), and undetermined causes (two). Group III was composed of 12 obese patients who otherwise demonstrated no evidence of cardiopulmonary disease. Their mean body weight was $112 \mathrm{~kg}$; mean height, $170 \mathrm{~cm}$; and mean body surface area, $2.22 \mathrm{~m}^{2}$. The normal controls were healthy male and female laboratory personnel and student nurses, ranging in age from 18 to 34 years.

Procedure and calculations. The subjects, resting and recumbent, with a noseclip applied, breathed through a tightly fitting rubber mouthpiece attached to a two-way plastic valve having a dead space of $40 \mathrm{ml}$. Arterial blood and expired gas were sampled simultaneously during a 
period of room air breathing, and again after the subjects had breathed nearly pure oxygen, delivered on demand, usually for 20 to 30 minutes, but always for at least 10 minutes. The air and oxygen studies were performed within 1 hour.

Expired ventilation was recorded on a Tissot spirometer. Inspired and expired gases were analyzed for oxygen and carbon dioxide by the Scholander apparatus (20), and expired gas nitrogen was measured by the nitrogen meter. Arterial blood carbon dioxide tension $\left(\mathrm{Pa}_{\mathrm{CO}_{2}}\right)$ was determined by the bubble equilibration technique of Riley, Campbell, and Shepard (21), or by the electrode of Severinghaus and Bradley (22). Arterial blood oxygen tension $\left(\mathrm{Pa}_{\mathrm{CO}_{2}}\right)$ was measured in vivo, or in vitro at $37.5^{\circ} \mathrm{C}$ by a needle electrode $(23)$; when applicable, it was also measured by the Riley method (21).

Calculation of venous admixture was based on the equation:

$$
\dot{Q}_{v a} / \dot{Q}_{t}=\left(C_{\dot{c}}-C_{a}\right) /\left(C_{\dot{c}}-C_{\bar{v}}\right),
$$

where $\dot{Q}_{v a} / \dot{Q}_{\iota}$ is the venous admixture ratio of the total pulmonary blood flow, and $C_{\dot{c}}, C_{a}$, and $C_{\bar{v}}$ are the oxygen content in pulmonary end-capillary, systemic arterial, and mixed venous blood, respectively. (For simpler nomenclature, the subscript $\mathrm{O}_{2}$ has been omitted, where possible without ambiguity, from this equation and those to follow.)

Substituting oxygen saturation $(S)$ for oxygen content, Equation 1 becomes:

$$
\dot{Q}_{v a} / \dot{Q}_{t}=\left(S_{\dot{c}}-S_{a}\right) /\left(S_{\dot{c}}-S_{\bar{v}}\right) .
$$

In order to include in the estimate of venous admixture the contribution due to poor diffusion, the following modification of Equation 2 is necessary:

$$
\dot{Q}_{v a} / \dot{Q}_{t}=\left(S_{A}-S_{a}\right) /\left(S_{A}-S_{\bar{v}}\right),
$$

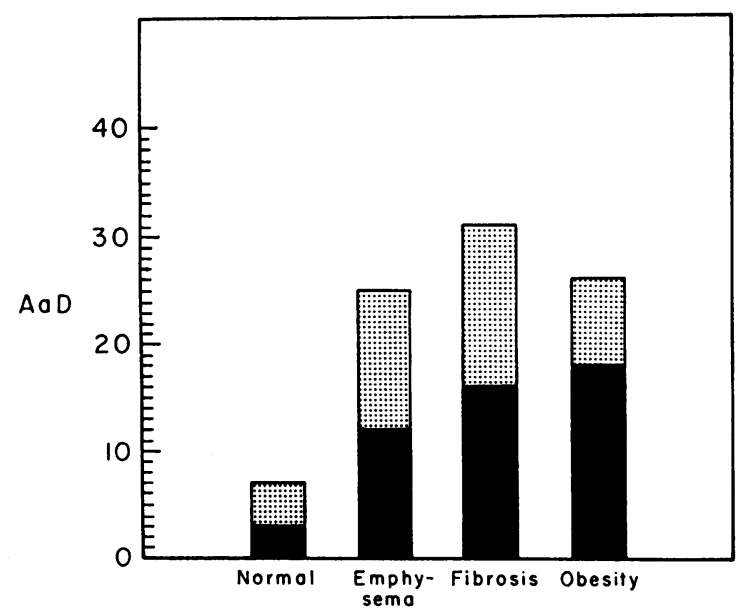

Fig. 1. Mean alveolar-ARterial OXYGen tension DIFFERENCE (AaD) IN NORMAL SUBJECTS AND IN PATIENTS WITH EMPHYSEMA, DIFFUSE PULMONARY FIBROSIS, OR OBESITY. Height of bars represents total AaD during air breathing, and blackened segment, portion due to venous admixture after oxygen was breathed. where $S_{A}$ is the saturation of blood if it were in complete equilibrium with alveolar oxygen. We used this equation, previously discussed elsewhere (24), to calculate venous admixture during air breathing. The value of $S_{A}-S_{\bar{v}}$ was assumed to be $25 \%$.

During $100 \%$ oxygen breathing, pulmonary endcapillary oxygen tension is that of alveolar gas, and if pulmonary capillary and peripheral arterial blood are both fully saturated, the difference in their oxygen content is due solely to the oxygen in physical solution. Thus Equation 1 becomes:

$\dot{Q}_{v a} / \dot{Q}_{l}=\left[\left(P_{A}-P_{a}\right) 0.0031\right] /\left[C_{a}+\left(P_{A}-P_{a}\right) 0.0031\right]-C_{\tilde{v}}$,

where $P_{A}$ is the "effective" alveolar oxygen tension (2), other symbols are as defined above, and 0.0031 is the solubility coefficient for oxygen in whole blood, expressed as volumes per $100 \mathrm{ml}$ per millimeters $\mathrm{Hg}$ of oxygen tension. The denominator was assumed to be 5 volumes per $100 \mathrm{ml}$.

$\mathrm{PAO}_{2}$ was calculated from the equation:

$$
\mathrm{PAO}_{2}=\mathrm{PIO}_{2}-\left(\mathrm{PaCO}_{2} / \mathrm{PECO}_{2}\right)\left(\mathrm{PIO}_{2}-\mathrm{PEO}_{2}\right) \text {, }
$$

where $\mathrm{P}_{\mathrm{O}_{2}}$ is inspired oxygen tension, $\mathrm{PE}_{\mathrm{O}}$ is expired oxygen tension, and $\mathrm{PE}_{\mathrm{CO}_{2}}$ is expired $\mathrm{CO}_{2}$ tension.

Pulmonary diffusing capacity was determined for carbon monoxide by the steady-state, physiologic dead-space method (25) in two patients, and for oxygen (3) in four.

To assess the magnitude of the $A a D$ resulting from atelectasis, we measured it in 15 patients immediately after four deep breaths at the end of the nitrogen washout period. This was prompted by the observations that forcible inflation of the lungs reverses the alveolar closure occurring in anesthetized dogs (26), and that deeper inspiration raised arterial oxygen tension in hypoxemic obese subjects (27).

\section{RESULTS}

As originally formulated, the concept of venous admixture includes the distribution and direct shunting components of the $\mathrm{AaD}(1-3)$, but in this presentation, the term is used to describe the combined effects of all the mechanisms responsible for the $\mathrm{AaD}$, measured at rest during air or oxygen breathing. This usage is justifiable, since under these circumstances, the contribution of diffusion barriers to the $\mathrm{AaD}$ is either negligible $(10,28)$, or, in extreme impairment of diffusion, inseparable from the distribution component (24).

In six normal subjects (Table I) breathing air, the $A a D$ ranged from 3 to 11 and averaged $7 \mathrm{~mm}$ $\mathrm{Hg}$. This corresponded to an estimated venous admixture of $3.3 \pm 1.8 \%$ of the cardiac output. During oxygen breathing, the mean $\mathrm{AaD}$ was 26 with a range from 7 to $40 \mathrm{~mm} \mathrm{Hg}$. This was equivalent to a shunt of $1.6 \pm 0.7 \%$, which would 
TABLE I

Alveolar gas and arterial blood $P_{\mathrm{O}_{2}}$ and $\mathrm{P}_{\mathrm{CO}_{2}}$, and pulmonary venous admixture during air and $100 \% \mathrm{O}_{2}$ breathing in six normal subjects*

\begin{tabular}{|c|c|c|c|c|c|c|c|c|c|c|c|c|c|}
\hline \multirow[b]{2}{*}{ Subject } & \multirow[b]{2}{*}{ DBP } & \multicolumn{5}{|c|}{ Air } & \multicolumn{7}{|c|}{ Oxygen } \\
\hline & & $\mathrm{PaCO}_{2}$ & $\mathrm{PAO}_{2}$ & $\mathrm{PaO}_{2}$ & $\mathrm{AaD}$ & $\begin{array}{l}\dot{\mathrm{Q}}_{\mathrm{va}} / \dot{\mathrm{Q}}_{\mathrm{t}} \\
\times 100\end{array}$ & $\mathrm{FIO}_{2}$ & Time & $\mathrm{PaCO}_{2}$ & $\mathrm{PAO}_{2}$ & $\mathrm{~Pa}_{2}$ & $\mathrm{AaD}$ & $\begin{array}{c}Q_{\mathrm{va}} / \dot{Q}_{\mathrm{vt}} \\
\times 100\end{array}$ \\
\hline & $m m \mathrm{Hg}$ & $m m \mathrm{Hg}$ & $m m \mathrm{Hg}$ & $m m \mathrm{Hg}$ & $m m ~ H g$ & $\%$ & & $\min$ & $m m \mathrm{Hg}$ & $m m ~ H g$ & $m m \mathrm{Hg}$ & $m m \mathrm{Hg}$ & $\%$ \\
\hline L.N. & 717 & 43 & 97 & 94 & 3 & 1.5 & 0.99 & 10 & 36 & 659 & 636 & 23 & 1.4 \\
\hline C.B. & 711 & 41 & 99 & 88 & 11 & 5.5 & 0.99 & 10 & 35 & 650 & 618 & 32 & 2.0 \\
\hline J.J. & 716 & 40 & 101 & 94 & 7 & 3.5 & 0.99 & 10 & 42 & 654 & 631 & 23 & 1.4 \\
\hline A. $K$. & 711 & 38 & 102 & 92 & 10 & 5.0 & 0.99 & 10 & 38 & 660 & 620 & 40 & 2.5 \\
\hline S.H. & 722 & 40 & 102 & 98 & 4 & 2.0 & 0.99 & 11 . & 36 & 662 & 655 & 7 & .4 \\
\hline S.B. & 715 & 42 & 98 & 93 & 5 & 2.5 & 0.99 & 15 & 41 & 650 & 617 & 33 & 2.0 \\
\hline
\end{tabular}

${ }^{*} \mathrm{DBP}=$ dry barometric pressure, calculated as ambient barometric pressure $-\mathrm{PH}_{2} \mathrm{O}$ at $37^{\circ} \mathrm{C}(47) . \quad \mathrm{Pa} \mathrm{Co}_{2}=$ ar terial blood carbon dioxide tension; $\mathrm{PAO}_{2}=$ calculated "effective" alveoląr gas oxygen tension; $\mathrm{Pa}_{\mathrm{O}_{2}}=$ arterial blood oxygen tension; $\mathrm{AaD}=$ alveolar-arterial oxygen tension difference; $\dot{\mathrm{Q}}_{\mathrm{va}} / \dot{\mathrm{Q}}_{\mathrm{t}} \times 100=$ venous admixture, percentage of total pulmonary blood flow; $\mathrm{F}_{\mathrm{I}_{2}}=$ dry inspired oxygen concentration; and time $=$ duration of oxygen breathing.

account for an $\mathrm{AaD}$ of about $3 \mathrm{~mm} \mathrm{Hg}$ during air breathing.

All patients demonstrated some degree of increase in the $\mathrm{AaD}$ and the venous admixture (Tables II-V). In the air studies, the mean values and standard deviations of the $\mathrm{AaD}$ were $25 \pm 10,31 \pm 8$, and $26 \pm 10 \mathrm{~mm} \mathrm{Hg}$, respectively, in the three groups. During oxygen breathing, these values were $120 \pm 52,134 \pm 62$, and $147 \pm 58 \mathrm{~mm} \mathrm{Hg}$, corresponding to shunts of $7.4 \pm 4,8.3 \pm 4$, and $9.1 \pm 5 \%$.

The values for the component of the air breathing $\mathrm{AaD}$ resulting from these estimates of shunt measured on oxygen were calculated by use of the charts of Riley, Cournand, and Donald (3);
Figure 1 gives the means for each group of patients and for the control subjects, together with the mean total $\mathrm{AaD}$.

The inspiration of four deep breaths at the end of the nitrogen washout period (Table VI) decreased the venous admixture in six obese patients (from $12.4 \pm 5.8$ to $9 \pm 2.3 \%, \mathrm{p}<0.05$ ). There was a mean slight fall in five patients with emphysema $(p>0.1)$ and no fall $(p>0.8)$ in four patients with diffuse pulmonary fibrosis. The changes in alveolar gas and arterial blood $\mathrm{Po}_{2}$ and $\mathrm{PCO}_{2}$ are shown in Table VI.

During oxygen breathing, $\mathrm{Pa}_{\mathrm{CO}_{2}}$ remained within normal limits in all six normal subjects. Oxygen breathing, however, induced or aggra-

TABLE II

Alveolar gas and arterial blood $P_{\mathrm{O}_{2}}$ and $\mathrm{P}_{\mathrm{CO}_{2}}$, and pulmonary venous admixture during air and $100 \% \mathrm{O}_{2}$ breathing in 15 patients with obstructive pulmonary emphysema (group I)*

\begin{tabular}{|c|c|c|c|c|c|c|c|c|c|c|c|c|c|}
\hline \multirow[b]{2}{*}{ Patient } & \multirow[b]{2}{*}{ DBP } & \multicolumn{5}{|c|}{ Air } & \multicolumn{7}{|c|}{ Oxygen } \\
\hline & & $\mathrm{PacO}_{2}$ & $\mathrm{PAO}_{2}$ & $\mathrm{PaO}_{2}$ & $\mathrm{AaD}$ & $\underset{\times 100}{\dot{\mathrm{Q}}_{\mathrm{va}} / \dot{\mathrm{Q}}_{\mathrm{t}}}$ & $\mathrm{FIO}_{2}$ & Time & $\mathrm{PaCO}_{2}$ & $\mathrm{PAO}_{2}$ & $\mathrm{PaO}_{2}$ & $\mathrm{AaD}$ & $\begin{array}{l}\dot{Q}_{\mathrm{va}} / \dot{Q}_{\mathrm{t}} \\
\times 100\end{array}$ \\
\hline & $m m \mathrm{Hg}$ & $m m \mathrm{Hg}$ & $m m \mathrm{Hg}$ & $m m H g$ & $m m \mathrm{Hg}$ & $\%$ & & $\min$ & $m m H g$ & $m m H g$ & $m m H g$ & $m m \mathrm{Hg}$ & $\%$ \\
\hline W.S. & 724 & 35 & 108 & 73 & 35 & 19 & 0.97 & 15 & 36 & 660 & 549 & 111 & 6.9 \\
\hline A.H. & 709 & 38 & 101 & 82 & 19 & 14 & 0.95 & 15 & 40 & 641 & 587 & 54 & 3.3 \\
\hline R.O. & 707 & 38 & 101 & 68 & 33 & 27 & 0.95 & 15 & 41 & 638 & 517 & 121 & 7.5 \\
\hline W.J. & 709 & 38 & 101 & 74 & 27 & 19 & 0.95 & 15 & 42 & 639 & 487 & 152 & 9.4 \\
\hline N.A. & 720 & 49 & 93 & 55 & 38 & 38 & 0.99 & 25 & 60 & 636 & 448 & 188 & 11.7 \\
\hline T.P. & 720 & 40 & 102 & 66 & 36 & 26 & 0.99 & 30 & 47 & 643 & 582 & 61 & 3.8 \\
\hline A.C. & 718 & 39 & 102 & 65 & 37 & 27 & 0.99 & 15 & 43 & 647 & 506 & 141 & 8.7 \\
\hline R.S. & 721 & 43 & 98 & 77 & 21 & 12 & 0.95 & 15 & 44 & 649 & 575 & 74 & 4.6 \\
\hline D.R. & 710 & 40 & 100 & 82 & 18 & 10 & 0.99 & 15 & 40 & 642 & 603 & 39 & 2.4 \\
\hline P.H. & 705 & 69 & 78 & 46 & 32 & 50 & 0.99 & 20 & 75 & 610 & 383 & 227 & 14.1 \\
\hline J.S. & 713 & 45 & 94 & 76 & 18 & 12 & 0.99 & 25 & 51 & 648 & 537 & 111 & 6.9 \\
\hline J.B. & 713 & 50 & 91 & 84 & 7 & 4 & 0.99 & 15 & 51 & 644 & 566 & 78 & 4.8 \\
\hline R.N. & 715 & 40 & 101 & 85 & 16 & 8 & 0.99 & 12 & 41 & 668 & 583 & 85 & 5.3 \\
\hline J.P. & 716 & 58 & 79 & 56 & 23 & 28 & 0.99 & 27 & 62 & 623 & 512 & 111 & 6.9 \\
\hline B.P. & 714 & 62 & 74 & 61 & 13 & 17 & 0.99 & 20 & 64 & 625 & 383 & 242 & 15.0 \\
\hline
\end{tabular}

* Symbols as in Table I. 
TABLE III

Alveolar gas and arterial blood $P_{O_{2}}$ and $P_{C o}$, and pulmonary venous admixture during air and $100 \% \mathrm{O}_{2}$ breathing in 14 patients with diffuse pulmonary fibrosis or infiltration (group II)*

\begin{tabular}{|c|c|c|c|c|c|c|c|c|c|c|c|c|c|c|}
\hline \multirow[b]{2}{*}{ Patient } & \multirow[b]{2}{*}{ DBP } & \multicolumn{6}{|c|}{ Air } & \multicolumn{7}{|c|}{ Oxygen } \\
\hline & & $\mathrm{PaCO}_{2}$ & $\mathrm{PAO}_{2}$ & $\mathrm{~Pa}_{2}$ & $\mathrm{AaD}$ & 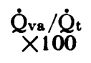 & $D_{L}$ & $\mathrm{FlO}_{2}$ & Time & $\mathrm{PaCO}_{2}$ & $\mathrm{PAO}_{2}$ & $\mathrm{~Pa}_{2}$ & $\mathrm{AaD}$ & $\begin{array}{l}Q_{\text {va } / Q_{t}} \\
\times 100\end{array}$ \\
\hline & $m m \mathrm{Hg}$ & $m m \mathrm{Hg}$ & $\mathrm{mm} \mathrm{Hg}$ & $\mathrm{mm} \mathrm{Hg}$ & $m m \mathrm{Hg}$ & $\%$ & $\underset{H g / m i n}{m l / m m}$ & & $\min$ & $m m \mathrm{Hg}$ & $m m \mathrm{Hg}$ & $m m \mathrm{Hg}$ & $m m \mathrm{Hg}$ & $\%$ \\
\hline G.H. & 712 & 36 & 105 & 73 & 32 & 18 & & 0.97 & 10 & 36 & 648 & 610 & 38 & 2.4 \\
\hline K.B. & 709 & 38 & 101 & 65 & 36 & 26 & $7.7 \dagger$ & 0.95 & 15 & 35 & 646 & 500 & 146 & 9.1 \\
\hline C. K. & 707 & 41 & 103 & 57 & 46 & 38 & $2.9 \ddagger$ & 0.99 & 20 & 50 & 650 & 436 & 214 & 13.3 \\
\hline Q.G. & 711 & 43 & 96 & 65 & 31 & 25 & & 0.99 & 15 & 43 & 640 & 407 & 233 & 14.4 \\
\hline L.S. & 711 & 40 & 100 & 64 & 36 & 27 & & 0.99 & 20 & 41 & 647 & 527 & 120 & 7.4 \\
\hline H.C. & 716 & 40 & 101 & 75 & 26 & 15 & & 0.99 & 20 & 51 & 637 & 572 & 65 & 4.0 \\
\hline V.S. & 718 & 42 & 98 & 75 & 23 & 14 & & 0.99 & 20 & 43 & 666 & 561 & 105 & 6.5 \\
\hline S.J. & 716 & 40 & 102 & 84 & 18 & 9 & $15.3 t$ & 0.99 & 16 & 38 & 649 & 560 & 89 & 5.5 \\
\hline W.M. & 715 & 35 & 107 & 66 & 41 & 27 & & 0.99 & 22 & 30 & 664 & 588 & 76 & 4.7 \\
\hline V.A.S. & 709 & 41 & 98 & 54 & 44 & 41 & $5.7 \ddagger$ & 0.99 & 15 & 61 & 638 & 442 & 196 & 12.2 \\
\hline V.H. & 712 & 39 & 101 & 75 & 26 & 15 & & 0.99 & 26 & 46 & 626 & 446 & 180 & 11.2 \\
\hline C.S. & 712 & 39 & 101 & 75 & 26 & 15 & & 0.99 & 20 & 39 & 645 & 473 & 172 & 10.6 \\
\hline R.G. & 716 & 45 & 98 & 76 & 22 & 13 & $27.6 \dagger$ & 0.99 & 16 & 45 & 654 & 586 & 68 & 4.2 \\
\hline G.J. & 715 & 40 & 106 & 78 & 28 & 15 & $8.6 \dagger$ & 0.99 & 22 & 41 & 668 & 489 & 179 & 11.1 \\
\hline
\end{tabular}

${ }^{*} D_{L}=$ diffusing capacity of the lung for oxygen $(\dagger)$ or for carbon monoxide $(\ddagger)$; ot her symbols as in Table I.

vated carbon dioxide retention in six of the emphysematous patients, in two obese patients, and, unexpectedly, in four patients with pulmonary fibrosis.

\section{DISCUSSION}

Interpretation of the results is based on comparison of the calculated venous admixture on air and on oxygen breathing. When pure oxygen is breathed and alveolar nitrogen washout completed, the diffusion and distribution components become negligible and the $\mathrm{AaD}$ can then result only from 1) direct venous admixture, either through normally existing channels or through direct pulmonary arteriovenous shunts or portalmediastinal-pulmonary venous communications, and 2) perfusion of alveoli that cannot receive any of the inspired oxygen because they are atelectatic, or completely occluded by exudate or thickened walls.

Accuracy of the methods. The procedures and calculations used in this investigation necessitated a number of assumptions and simplifications. The effects of these assumptions on the accuracy of the results, and the reliability of the methods in general, are discussed below.

TABLE IV

Alveolar gas and arterial blood $P_{O_{2}}$ and $P_{C O_{2}}$ and pulmonary venous admixture during air and $100 \% \mathrm{O}_{2}$ breathing in 12 obese patients (group III)*

\begin{tabular}{|c|c|c|c|c|c|c|c|c|c|c|c|c|c|}
\hline \multirow[b]{2}{*}{ Patient } & \multirow[b]{2}{*}{$\mathrm{DBP}$} & \multicolumn{5}{|c|}{ Air } & \multicolumn{7}{|c|}{ Oxygen } \\
\hline & & $\mathrm{PaCO}_{2}$ & $\mathrm{PAO}_{2}$ & $\mathrm{~Pa}_{2}$ & $\mathrm{AaD}$ & $\begin{array}{c}\overline{\dot{Q}_{\mathrm{va}} / \dot{\mathrm{Q}}_{\mathrm{t}}} \\
\times 100\end{array}$ & $\mathrm{FIO}_{2}$ & Time & $\mathrm{PaCO}_{2}$ & $\mathrm{PAO}_{2}$ & $\mathrm{~Pa}_{2}$ & $\mathrm{AaD}$ & $\begin{array}{l}\dot{\mathrm{Q}}_{\mathrm{VR}} / \dot{\mathrm{Q}}_{\mathrm{t}} \\
\times 100\end{array}$ \\
\hline & $m m H g$ & $m m H g$ & $m m H g$ & $m m ~ H g$ & $m m ~ H g$ & $\%$ & & $\min$ & $m m ~ H g$ & $m m ~ H g$ & $m m ~ H g$ & $m m \mathrm{Hg}$ & $\%$ \\
\hline A.A. & 713 & 35 & 106 & 60 & 46 & 35 & 0.97 & 10 & 35 & 668 & 435 & 233 & 14.4 \\
\hline C. H. & 712 & 34 & 107 & 79 & 28 & 14 & 0.97 & 10 & 34 & 668 & 587 & 81 & 5.0 \\
\hline S.B. & 715 & 38 & 103 & 86 & 17 & 8 & 0.97 & 10 & 38 & 656 & 494 & 162 & 10.0 \\
\hline A.C. & 718 & & & & & & 0.95 & 10 & 59 & 632 & 441 & 191 & 11.8 \\
\hline J.F. & 718 & 39 & 102 & 84 & 18 & 10 & 0.95 & 10 & 46 & 644 & 472 & 172 & 10.7 \\
\hline G.M. & 718 & 42 & 98 & 73 & 25 & 17 & 0.95 & 10 & 39 & 636 & 505 & 131 & 8.1 \\
\hline A.B. & 722 & 40 & 102 & 87 & 15 & 8 & 0.99 & 14 & 41 & 663 & 601 & 62 & 3.8 \\
\hline A. H. & 711 & 34 & 107 & 71 & 36 & 22 & 0.99 & 12 & 41 & 654 & 548 & 106 & 6.6 \\
\hline E.D. & 716 & 34 & 107 & 87 & 20 & 9 & 0.99 & 15 & 40 & 654 & 583 & 78 & $\begin{array}{l}0.0 \\
4.8\end{array}$ \\
\hline S.M.B. & 719 & 46 & 94 & 78 & 16 & 10 & 0.99 & 20 & 48 & 661 & 517 & 144 & $\begin{array}{l}4.0 \\
8.9\end{array}$ \\
\hline J.D. & 719 & 51 & 89 & 56 & 33 & 35 & 0.99 & 21 & 68 & 626 & 392 & 234 & $\begin{array}{r}0.5 \\
14.5\end{array}$ \\
\hline M.T. & 709 & 35 & 117 & 89 & 28 & 11 & 0.99 & 10 & 43 & 659 & 483 & 129 & 8.0 \\
\hline
\end{tabular}

* Symbols as in Table I. 
TABLE V

Mean values and standard deviations of measurements during air and oxygen breathing*

\begin{tabular}{|c|c|c|c|c|c|c|c|c|}
\hline \multirow[b]{2}{*}{ Diagnosis } & \multicolumn{4}{|c|}{ Air } & \multicolumn{4}{|c|}{ Oxygen } \\
\hline & $\mathrm{PAO}_{2}$ & $\mathrm{~Pa}_{2}$ & $\mathrm{AaD}$ & $\begin{array}{c}\dot{Q}_{\mathrm{va}} / \dot{Q}_{t} \\
\times 100\end{array}$ & $\mathrm{PAO}_{2}$ & $\mathrm{~Pa}_{2}$ & $\mathrm{AaD}$ & $\begin{array}{c}\mathrm{Q}_{\mathrm{va}} / \mathrm{Q}_{\mathrm{t}} \\
\times 100\end{array}$ \\
\hline $\begin{array}{l}\text { Normal } \\
\text { Emphysema } \\
\text { Fibrosis } \\
\text { Obesity }\end{array}$ & $\begin{array}{r}100 \pm 2 \\
95 \pm 10 \\
101 \pm 3 \\
103 \pm 7\end{array}$ & $\begin{array}{l}93 \pm 3 \\
70 \pm 11 \\
70 \pm 8 \\
77 \pm 11\end{array}$ & $\begin{array}{r}7 \pm 3 \\
25 \pm 10 \\
31 \pm 8 \\
26 \pm 10\end{array}$ & $\begin{array}{l}3.3 \pm 1.8 \\
20.7 \pm 12 \\
21.3 \pm 10 \\
16.3 \pm 10\end{array}$ & $\begin{array}{l}656 \pm 5 \\
641 \pm 12 \\
648 \pm 12 \\
652 \pm 14\end{array}$ & $\begin{array}{l}630 \pm 15 \\
521 \pm 70 \\
514 \pm 67 \\
505 \pm 66\end{array}$ & $\begin{array}{r}26 \pm 12 \\
120 \pm 52 \\
134 \pm 62 \\
147 \pm 58\end{array}$ & $\begin{array}{l}1.6 \pm 0.7 \\
7.4+4 \\
8.3 \pm 4 \\
9.1 \pm 5\end{array}$ \\
\hline
\end{tabular}

* Symbols as in Table I.

1) The measurement of $\mathrm{Pa}_{02}$ by the needle electrode is subject to error due to a small flow artifact, temperature sensitivity, and drift in current output (23). We attempted to minimize these errors by performing frequent calibrations of the electrode in gas-equilibrated water samples, and by making all in vitro measurements at $37.5^{\circ} \mathrm{C}$.

2) The temperature of the pulmonary capillary and of systemic arterial blood was assumed to be $37.5^{\circ} \mathrm{C}$. An underestimation of this temperature would result in an underestimation of $\mathrm{Pa}_{\mathrm{O}_{2}}, \mathrm{~Pa}_{\mathrm{CO}_{2}}$, and $\mathrm{P}_{\mathrm{A}_{2} \mathrm{O}}$. All of these errors would combine to lead to an overestimation of the $\mathrm{AaD}$ by as much as $8.5 \mathrm{~mm} \mathrm{Hg}$ per degree Centigrade in a subject breathing room air (29), and $38 \mathrm{~mm} \mathrm{Hg}$ per degree Centigrade in a subject breathing oxygen. Preliminary work by Farhi, Edwards, and Velasquez (30) confirms that pulmonary capillary temperature in normal resting man is approximately $37.5^{\circ} \mathrm{C}$.

$3)$ For the calculation of venous admixture (Equations 3 and 4, above), all possible sources of venous admixture were considered collectively

TABLE VI

Effect of four deep breaths at the end of nitrogen washout on the alveolar-arterial oxygen tension difference and pulmonary venous admixture during oxygen breathing*

\begin{tabular}{|c|c|c|c|c|c|c|c|c|c|c|c|c|}
\hline \multirow[b]{2}{*}{ Diagnosis } & \multirow[b]{2}{*}{ Patient } & \multicolumn{6}{|c|}{ Tidal breathing } & \multicolumn{5}{|c|}{ After four deep breaths } \\
\hline & & Time & $\mathrm{PaCO}_{2}$ & $\mathrm{PAO}_{2}$ & $\mathrm{~Pa}_{2}$ & $\mathrm{AaD}$ & $\begin{array}{l}\dot{Q}_{\mathrm{va}} / \dot{Q}_{\mathrm{t}} \\
\times 100\end{array}$ & $\mathrm{PaCO}_{2}$ & $\mathrm{PAO}_{2}$ & $\mathrm{~Pa}_{2}$ & $\mathrm{AaD}$ & $\begin{array}{l}\dot{\mathrm{Q}}_{\mathrm{va}} / \dot{\mathrm{Q}}_{t} \\
\times 100\end{array}$ \\
\hline \multirow{2}{*}{ I. Emphysema } & & $\min$ & $m m \mathrm{Hg}$ & $m m \mathrm{Hg}$ & $m m \mathrm{Hg}$ & $m m \mathrm{Hg}$ & $\%$ & $m m \mathrm{Hg}$ & $m m \mathrm{Hg}$ & $m m \mathrm{Hg}$ & $m m \mathrm{Hg}$ & $\%$ \\
\hline & $\begin{array}{l}\text { N.A. } \\
\text { J.S. } \\
\text { P.H. } \\
\text { R.N. } \\
\text { J.C. } \\
\text { Mean } \\
\text { SD } \\
\text { p }\end{array}$ & $\begin{array}{l}25 \\
25 \\
20 \\
12 \\
20\end{array}$ & $\begin{array}{l}60 \\
51 \\
75 \\
41 \\
45 \\
54 \\
14\end{array}$ & $\begin{array}{r}636 \\
648 \\
610 \\
668 \\
658 \\
644 \\
22\end{array}$ & $\begin{array}{r}448 \\
537 \\
383 \\
583 \\
474 \\
485 \\
78\end{array}$ & $\begin{array}{r}188 \\
111 \\
227 \\
85 \\
184 \\
159 \\
59\end{array}$ & $\begin{array}{r}11.7 \\
6.9 \\
14.1 \\
5.3 \\
11.4 \\
9.9 \\
3.6\end{array}$ & $\begin{array}{l}55 \\
47 \\
74 \\
41 \\
43 \\
52 \\
13\end{array}$ & $\begin{array}{r}641 \\
652 \\
611 \\
668 \\
660 \\
646 \\
22\end{array}$ & $\begin{array}{r}484 \\
573 \\
401 \\
583 \\
503 \\
509 \\
73\end{array}$ & $\begin{array}{r}157 \\
79 \\
210 \\
85 \\
157 \\
137 \\
55\end{array}$ & $\begin{array}{r}9.7 \\
4.9 \\
13 \\
5.3 \\
9.7 \\
8.5 \\
3.4 \\
>0.1\end{array}$ \\
\hline II. Fibrosis & $\begin{array}{l}\text { C.S. } \\
\text { M.L.H. } \\
\text { R.G. } \\
\text { G.J. } \\
\quad \text { Mean } \\
\text { SD } \\
\text { p }\end{array}$ & $\begin{array}{l}20 \\
20 \\
16 \\
22\end{array}$ & $\begin{array}{r}39 \\
56 \\
45 \\
41 \\
45 \\
8\end{array}$ & $\begin{array}{r}645 \\
632 \\
654 \\
668 \\
650 \\
15\end{array}$ & $\begin{array}{r}473 \\
517 \\
586 \\
489 \\
516 \\
50\end{array}$ & $\begin{array}{r}172 \\
115 \\
68 \\
179 \\
134 \\
52\end{array}$ & $\begin{array}{r}10.6 \\
7.1 \\
4.2 \\
11.1 \\
8.3 \\
3.2\end{array}$ & $\begin{array}{r}32 \\
49 \\
45 \\
36 \\
41 \\
8\end{array}$ & $\begin{array}{r}652 \\
639 \\
654 \\
673 \\
655 \\
13\end{array}$ & $\begin{array}{r}486 \\
517 \\
563 \\
492 \\
515 \\
35\end{array}$ & $\begin{array}{r}166 \\
122 \\
91 \\
181 \\
140 \\
41\end{array}$ & $\begin{array}{r}10.3 \\
7.6 \\
5.6 \\
11.2 \\
8.7 \\
2.5 \\
>0.8\end{array}$ \\
\hline III. Obesity & $\begin{array}{l}\text { S.M.B. } \\
\text { A.C. } \\
\text { J.D. } \\
\text { F.M. } \\
\text { A.S. } \\
\text { M.T. } \\
\quad \text { Mean } \\
\quad \text { SD } \\
\text { p }\end{array}$ & $\begin{array}{l}20 \\
10 \\
21 \\
20 \\
18 \\
10\end{array}$ & $\begin{array}{l}48 \\
59 \\
68 \\
71 \\
45 \\
43 \\
56 \\
12\end{array}$ & $\begin{array}{r}661 \\
632 \\
626 \\
624 \\
630 \\
659 \\
639 \\
17\end{array}$ & $\begin{array}{l}517 \\
441 \\
392 \\
261 \\
540 \\
483 \\
439 \\
102\end{array}$ & $\begin{array}{r}144 \\
191 \\
234 \\
363 \\
90 \\
176 \\
200 \\
93\end{array}$ & $\begin{array}{r}8.9 \\
11.8 \\
14.5 \\
22.5 \\
5.6 \\
10.9 \\
12.4 \\
5.8\end{array}$ & $\begin{array}{r}45 \\
53 \\
65 \\
58 \\
42 \\
42 \\
51 \\
9\end{array}$ & $\begin{array}{l}664 \\
638 \\
629 \\
647 \\
633 \\
660 \\
645 \\
14\end{array}$ & $\begin{array}{r}535 \\
471 \\
469 \\
454 \\
542 \\
531 \\
500 \\
40\end{array}$ & $\begin{array}{r}129 \\
167 \\
160 \\
193 \\
91 \\
129 \\
145 \\
36\end{array}$ & $\begin{array}{c}7.9 \\
10.4 \\
9.9 \\
12 \\
5.6 \\
8 \\
9 \\
2.3 \\
<0.05\end{array}$ \\
\hline
\end{tabular}

* Symbols as in Table I. 
as one shunt-flow of blood having the same oxygen content as the mixed venous blood entering the pulmonary capillaries. This condition holds in the case of direct pulmonary arteriovenous communications and of blood perfusing alveoli that permit no oxygen transfer, but is only a rough approximation for other sources of venous admixture.

4) The use of an assumed value for the difference in oxygen content or saturation between blood in equilibrium with alveolar gas and mixed venous blood introduces a source of inaccuracy, but venous admixture is relatively insensitive to changes in this variable $(12,31)$.

5) In the use of data obtained during oxygen breathing to interpret observations made during air breathing, error could arise from neglect of such possible effects of oxygen breathing as $a$ ) the tendency of some poorly ventilated alveoli to become atelectatic, $b$ ) pulmonary vasodilatation and redistribution of pulmonary blood flow, and $c$ )

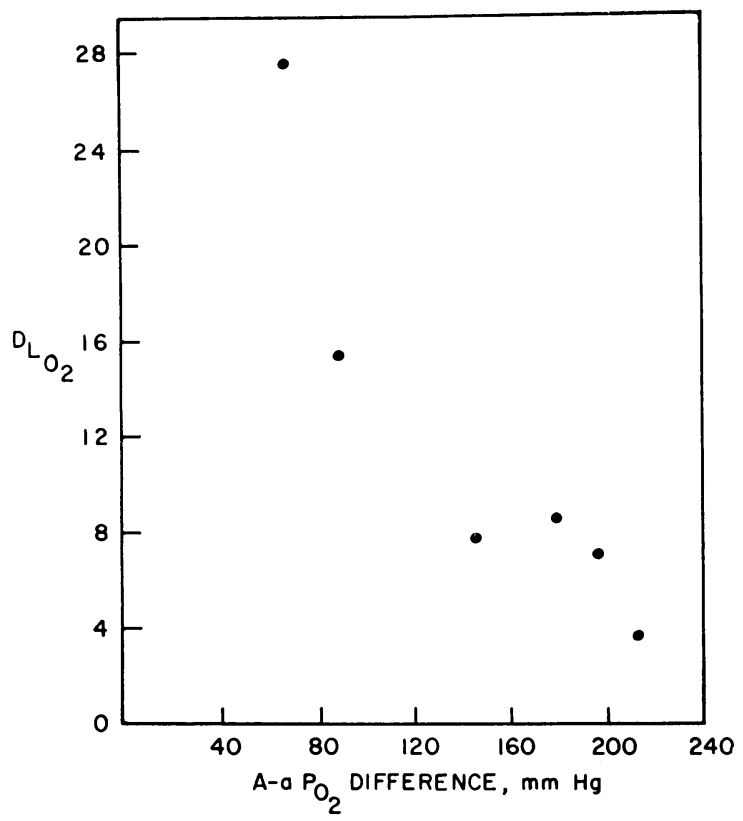

Fig. 2. Plot of pulmonary diffusing capacity for OXYGEN (DLo:) AGAINST ALVEOLAR-ARTERIAL OXYGEN PARTIAL PRESSURE DIFFERENCE, MEASURED DURING OXYGEN BREATHING, IN SIX PATIENTS WITH DIFFUSE DISEASES OF THE ALVEOLAR-CAPILlary BED. Values shown for Dlo. represent direct measurements in four patients (K.B., S.J., R.G., and G.J.), and calculations in two (C.K. and V.A.S.) of $1.23 \times$ measured diffusing capacity for carbon monoxide (data from Table III). change in the cardiac output. The magnitude of this error is difficult to predict, owing to the complex factors involved (32).

The AaD and pulmonary zenous admixture in normal man. The mean $\mathrm{AaD}$ in our normal subjects during oxygen breathing $(26 \pm 12 \mathrm{~mm} \mathrm{Hg}$ ) is somewhat higher than the values reported by Berggren $(11.3 \pm 1.5 \mathrm{~mm} \mathrm{Hg})(16)$ and by Wilson and associates $(16 \pm 11 \mathrm{~mm} \mathrm{Hg})(18)$, somewhat lower than the estimates of Morgan and Nahas $(57 \mathrm{~mm} \mathrm{Hg}$ ) (33), and of Fasciolo and Chiodi $(35.8 \pm 19.6 \mathrm{~mm} \mathrm{Hg})(17)$, and in close agreement with Finley's (15) data.

Our estimate of a direct shunt of about $1.6 \%$ of the cardiac output would account for an $\mathrm{AaD}$ of approximately $3 \mathrm{~mm} \mathrm{Hg}$ during air breathing. Since the effect of diffusion barriers could be neglected under the conditions of this study, the remainder of the AaD-namely, $4 \mathrm{~mm} \mathrm{Hg}$-must have been the result of nonuniform distribution of ventilation in relation to perfusion. A distribution component of this magnitude was calculated for upright subjects by West (34) and was quoted in a theoretical analysis by Farhi (35). Assuming even perfusion, and on the basis of heliummixing studies, Briscoe (36) predicted a mean $\mathrm{AaD}$ of $9 \mathrm{~mm} \mathrm{Hg}$ due to uneven ventilation-perfusion. The relatively large distribution fraction $(80 \%)$ of the AaD described by Asmussen and Nielsen $(37,38)$ is due to the larger total $\mathrm{AaD}$ $(17 \pm .97 \mathrm{~mm} \mathrm{Hg})$ in their subjects.

Venous admixture in emphysema. The presence of an increased $\mathrm{AaD}$ and venous admixture during oxygen breathing in emphysematous patients may be explained by several mechanisms. Two of these relate to the behavior of the least ventilated alveoli. When oxygen is breathed, these alveoli either become atelectatic and act as shunts, or remain open but nonventilated $(39,40)$. In the latter case, inspired oxygen could reach the alveoli by "diffusion respiration," but their washout of nitrogen might take longer than 1 hour (40). In this investigation, oxygen breathing was carried out for 15 to 30 minutes, which probably resulted in an incomplete nitrogen washout from such alveoli and thereby could account for a portion of the observed AaD. A third possible mechanism is that of augmented flow in the bronchial veins. The expansion of the broncho- 
pulmonary venous collateral circulation in advanced emphysema has been demonstrated by Liebow (41). Finally, although it is possible that direct pulmonary arteriovenous communications exist in some patients with chronic emphysema, Fritts and co-workers (19), using intravenous injection of krypton ${ }^{8,}$ dissolved in T-1824 dye, found $\mathrm{no}$ increase in pulmonary arteriovenous shunt-flow in eight emphysematous patients. These authors point out, however, that $\mathrm{Kr}^{85}$ and oxygen may not detect the same anatomic pathways.

Venous admixture against diffusion limitation in patients with diffuse pulmonary fibrosis or infiltration. The relationship between venous admixture during oxygen breathing and the pulmonary diffusing capacity for oxygen in six patients with diffuse alveolar-capillary disease is illustrated in Figure 2. It is apparent from this plot that as diffusing capacity worsens, so does venous admixture, suggesting that both effects are related to one mechanism that alters alveolar units in such a way that they cease to function as diffusing units and act instead as shunting units. This could result from obliteration of alveolar spaces, or marked thickening of the alveolar-capillary membrane $(10,24)$. In this respect, there is a striking resemblance between the relationship plotted in Figure 2 and that calculated by Finley, Swenson, and Comroe (10) for the change in diffusing capacity with increased thickness of the alveolar-capillary membrane.

In one patient (R.G.), and possibly in another (S.J.), the measured diffusing capacity for oxygen (27.6 and $15.3 \mathrm{ml}$ per $\mathrm{mm} \mathrm{Hg}$ per minute, respectively), was within normal limits, but the $\mathrm{AaD}$ was increased. This apparent discrepancy may be related to the error in estimating diffusing capacity by this method in resting subjects with little or no impairment of diffusion $(42,43)$. It is also possible that when relatively few alveolar units have become functionless, the increase in venous admixture would be apparent before any reduction in the overall diffusing capacity could be detected. The effect of unequal distribution of diffusion impairment on the $\mathrm{AaD}$ has been discussed by Piiper (44) and by Piiper, Haab, and Rahn (45).

The data reported here indicate that an increase in the shunt component of the $\mathrm{AaD}$ is a common finding in patients with diffuse alveolar-capillary disease. These patients have also been shown to have grossly uneven distribution of ventilation in relation to blood flow (10). Since these two mechanisms contribute more importantly to the altered gas exchange than the reduction in pulmonary diffusing capacity itself, one might question the applicability of the term "alveolar-capillary block" (46) in these cases. A pure form of diffusion limitation can be seen, however, during exercise at high altitude (47).

Increased venous admixture in obesity. The findings of an increased venous admixture that persisted to a large extent during oxygen breathing and decreased with deep inspiration are in keeping with the opinion, previously presented (27), that atelectasis is a major cause of hypoxemia in obesity. The data, however, do not rule out other mechanisms of venous admixture on oxygen.

Effect of deep breaths. The reduction in venous admixture on oxygen after the inspiration of four deep breaths was probably due to the opening of atelectatic alveoli. A similar effect has been noted by Finley and associates (48) in anesthetized dogs during positive-pressure breathing. The slight or absent fall in venous admixture observed respectively in the patients with obstructive emphysema or diffuse pulmonary fibrosis suggests that relatively little or no atelectasis was present.

\section{SUM M ARY}

1) Pulmonary venous admixture was determined during air breathing and after breathing $100 \%$ oxygen in 6 normal subjects, in 15 patients with chronic obstructive pulmonary emphysema, 14 with diffuse pulmonary fibrosis or infiltration, and 12 with marked obesity. 2) All groups of patients demonstrated a mean increase in venous admixture relative to the normal subjects. 3) Deep breathing reduced the shunt on oxygen in obese patients, but not in patients with emphysema or pulmonary fibrosis. 4) The shunt component remaining after nitrogen washout could be explained largely by the continued perfusion of alveoli that were atelectatic or otherwise nonventilated, or that permitted no oxygen diffusion. 


\section{ACKNOWLEDGMENT}

We are grateful to Zena Edwards, Betty Hom, Joanne Dorey, Jerry Noland, Elizabeth Haynie, and Richard Manson for their valuable assistance.

\section{REFERENCES}

1. Lilienthal, J. L., Jr., R. L. Riley, D. D. Proemmel, and R. E. Franke. An experimental analysis in man of the oxygen pressure gradient from alveolar air to arterial blood during rest and exercise at sea level and at altitude. Amer. J. Physiol. 1946, 147, 199.

2. Riley, R. L., and A. Cournand. Analysis of factors affecting partial pressures of oxygen and carbon dioxide in gas and blood of lungs: theory. J. appl. Physiol. 1951, 4, 77.

3. Riley, R. L., A. Cournand, and K. W. Donald. Analysis of factors affecting partial pressures of oxygen and carbon dioxide in gas and blood of lungs: methods. J. appl. Physiol. 1951, 4, 102.

4. Rahn, H., and W. O. Fenn. A Graphical Analysis of the Respiratory Gas Exchange. Washington, American Physiological Society, 1955, p. 14.

5. Forster, R. E. Exchange of gases between alveolar air and pulmonary capillary blood: pulmonary diffusing capacity. Physiol. Rev. 1957, 37, 391.

6. Roughton, F. J. W., and R. E. Forster. Relative importance of diffusion and chemical reaction rates in determining rate of exchange of gases in the human lung, with special reference to true diffusing capacity of pulmonary membrane and volume of blood in the lung capillaries. J. appl. Physiol. 1957, 11, 290.

7. Staub, N. C., J. M. Bish $\ulcorner$, and R. E. Forster. Importance of diffusion and chemical reaction rates in $\mathrm{O}_{2}$ uptake in the lung. J. appl. Physiol. 1962, $17,21$.

8. Briehl, R. W., and A. P. Fishman. Principles of the Bohr integration procedure and their application to measurement of diffusing capacity of the lung for oxygen. J. appl. Physiol. 1960, 15, 337.

9. Farhi, L. E., and H. Rahn. A theoretical analysis of the alveolar-arterial $\mathrm{O}_{2}$ difference with special reference to the distribution effect. J. appl. Physiol. 1955, 7, 699.

10. Finley, T. N., E. W. Swenson, and J. H. Comroe, Jr. The cause of arterial hypoxemia at rest in patients with "alveolar-capillary block syndrome." J. clin. Invest. 1962, 41, 618.

11. Briscoe, W. A., and A. Cournand. Uneven ventilation of normal and diseased lungs studied by an open-circuit method. J. appl. Physiol. 1959, 14, 284.

12. Briscoe, W. A. A method for dealing with data concerning uneven ventilation of the lung and its effects on blood gas transfer. J. appl. Physiol. 1959, 14, 291.
13. West, J. B., and C. T. Dollery. Distribution of blood flow and ventilation-perfusion ratio in the lung, measured with radioactive $\mathrm{CO}_{2}$. J. appl. Physiol. 1960, 15, 405.

14. Ball, W. C., Jr., P. B. Stewart, L. G. S. Newsham, and D. V. Bates. Regional pulmonary function studied with xenon $^{133}$. J. clin. Invest. 1962, 41, 519.

15. Finley, T. N. The determination of uneven pulmonary blood flow from the arterial oxygen tension during nitrogen washout. J. clin. Invest. 1961, 40, 1727.

16. Berggren, S. M. The oxygen deficit of arterial blood caused by non-ventilating parts of the lung. Acta physiol. scand. 1942, 4, suppl. 11.

17. Fasciolo, J. C., and H. Chiodi. Arterial oxygen pressure during pure $\mathrm{O}_{2}$ breathing. Amer. J. Physiol. 1946, 147, 54.

18. Wilson, R. H., R. V. Ebert, C. W. Borden, R. T. Pearson, R. S. Johnson, A. Falk, and M. E. Dempsey. The determinations of blood flow through nonventilated portions of the normal and diseased lung. Amer. Rev. Tuberc. 1953, 68, 177.

19. Fritts, H. W., Jr., A. Hardewig, D. F. Rochester, J. Durand, and A. Cournand. Estimation of pulmonary arteriovenous shunt-flow using intravenous injections of $\mathrm{T}-1824$ dye and $\mathrm{Kr}^{\mathrm{85}}$. J. clin. Invest. 1960, 39, 1841.

20. Scholander, P. F. Analyzer for accurate estimation of respiratory gases in one-half cubic centimeter samples. J. biol. Chem. 1947, 167, 235.

21. Riley, R. L., E. J. M. Campbell, and R. H. Shepard. A bubble method for estimation of $\mathrm{P}_{\mathrm{CO}_{2}}$ and $\mathrm{P}_{\mathrm{O}_{2}}$ in whole blood. J. appl. Physiol. 1957, 11, 245.

22. Severinghaus, J. W., and A. F. Bradley. Electrodes for blood $\mathrm{P}_{\mathrm{O}_{2}}$ and $\mathrm{P}_{\mathrm{CO}}$, determination. J. appl. Physiol. 1958, 13, 515.

23. Said, S. I., R. K. Davis, and J. L. Crosier. Continuous recording in vivo of arterial blood $\mathrm{P}_{\mathrm{O}_{2}}$ in dogs and man. J. appl. Physiol. 1961, 16, 1129.

24. Said, S. I., W. T. Thompson, Jr., J. L. Patterson, Jr., and D. L. Brummer. Shunting effect of extreme impairment of pulmonary diffusion. Bull. Johns Hopk. Hosp. 1960, 105, 255.

25. Filley, G. F., D. J. MacIntosh, and G. W. Wright. Carbon monoxide uptake and pulmonary diffusing capacity in normal subjects at rest and during exercise. J. clin. Invest. 1954, 33, 530.

26. Mead, J., and Collier, C. Relation of volume history of lungs to respiratory mechanics in anesthetized dogs. J. appl. Physiol. 1959, 14, 669.

27. Said, S. I. Abnormalities of pulmonary gas exchange in obesity. Ann. intern. Med. 1960, 53, 1121.

23. Staub, N. C. Is there ever a measurable alveolararterial $\mathrm{O}_{2}$ gradient due to diffusion? (abstract). Physiologist 1961, 4, 115.

29. Bradley, A. F., M. Stupfel, and J. W. Severinghaus. Effect of temperature on $\mathrm{P}_{\mathrm{CO}_{2}}$ and $\mathrm{P}_{\mathrm{O}_{2}}$ of blood in vitro. J. appl. Physiol. 1956, 9, 201. 
30. Farhi, L. E., A. W. T. Edwards, and T. Velasquez. Measurement of pulmonary capillary temperature (abstract). Physiologist 1961, 4, 33.

31. Riley, R. L., M. C. Riley, and H. McD. Hill. Diffuse pulmonary sarcoidosis: diffusing capacity during exercise and other lung function studies in relation to ACTH therapy. Bull. Johns Hopk. Hosp. 1952, 91, 345.

32. Fishman, A. P. Respiratory gases in the regulation of the pulmonary circulation. Physiol. Rev. 1961, $41,214$.

33. Morgan, E. H., and G. G. Nahas. Study of relationship of arterial oxygen tension to alveolar oxygen pressure in man, utilizing a polarometric method for whole blood (abstract). Amer. J. Physiol. $1950,163,736$.

34. West, J. B. Topographical differences in gas exchange in the lung (abstract). Fed. Proc. 1962, 21, 441 .

35. Farhi, L. Over-all alveolo-arterial gas pressure differences at rest. Proc. 22nd int. Congr. physiol. Sci. 1962, 1, 308.

36. Briscoe, W. A. Comparison between alveolo arterial gradient predicted from mixing studies and the observed gradient. J. appl. Physiol. 1959, 14, 299.

37. Asmussen, E., and M. Nielsen. Alveolo-arterial gas exchange at rest and during work at different $\mathrm{O}_{2}$ tensions. Acta physiol. scand. 1960, 50, 153.

38. Asmussen, E., and M. Nielsen. The contribution of the distribution factor to the $\mathrm{A}-\mathrm{a} \mathrm{P}_{\mathrm{O}_{2}}$ difference (a correction). Acta physiol. scand. 1961, 51, 385.

39. Briscoe, W. A., E. M. Cree, J. Filler, H. E. J. Houssay, and A. Cournand. Lung volume, alveolar ventilation and perfusion interrelationships in chronic pulmcnary emphysema. J. appl. Physiol. 1960, 15, 785.

40. Haab, P., J. Piiper, and H. Rahn. Attempt to demonstrate the distribution component of the alveolararterial oxygen pressure differen.e. J. appl. Physiol. 1960, 15, 235.

41. Liebow, A. A. The bronchopulmonary vencus collateral circulation with special reference to emphysema. Amer. J. Path. 1953, 29, 251.

42. Riley, R. L., R. H. Shepard, J. E. Cohn, D. G. Carroll, and B. W. Armstrong. Maximal diffusing capacity of the lungs. J. appl. Physiol. 1954, 6, 573 .

43. Forster, R. E. The determination and significance of the diffusing capacity of the lungs and its clinical application. Progr. cardiovasc. Dis. 1959, 1, 268.

44. Piiper, J. Unequal distribution of pulmonary diffusing capacity and the alveolar-arterial $\mathrm{P}_{\mathrm{O}_{2}}$ differences: theory. J. appl. Physiol. 1961, 16, 493.

45. Piiper, J., P. Haab, and H. Rahn. Unequal distribution of pulmonary diffusing capacity in t':e anesthetized dog. J. appl. Physiol. 1961, 16, 499.

46. Austrian, R., J. H. McClement, A. D. Renzetti, Jr., K. W. Donald, R. L. Riley, and A. Cournand. Clinical and physiologic features of some types of pulmonary diseases with impairment of alveolarcapillary diffusion. The syndrome of "alveolarcapillary block.” Amer. J. Med. 1951, 11, 667.

47. West, J. B., S. Lahiri, M. B. Gill, J. S. Milledge, L. G. C. E. Pugh, and M. P. Ward. Arterial oxygen saturation during exercise at high altitude. J. appl. Physiol. 1962, 17, 617.

48. Finley, T. N., C. Lenfant, P. Haab, J. Piiper, and H. Rahn. Venous admixture in the pulmonary circulation of anesthetized dogs. J. appl. Physiol. $1960,15,418$. 